\title{
Effect of the adsorption pH and temperature on the parameters of the Brouers-Sotolongo models
}

Taher Selmi $^{1 *}$, Mongi Seffen ${ }^{1}$, Alain Celzard ${ }^{2}$, Vanessa Fierro $^{2}$

${ }^{1}$ Laboratory of Energy and Materials (LabEM). ESSTHS, BP 4011Hammam Sousse (Sousse University-Tunisia).

${ }^{2}$ Institut Jean Lamour, UMR CNRS 7198, 27 Rue Philippe Séguin, BP 21042, 88051 Epinal Cedex 9, France

* Corresponding author (Taher Selmi) Tel: + 21622284494

E-mail address: taher-selmi@ hotmail.com 


\begin{abstract}
The goal of the present paper was to elucidate if - and how - the parameters of the Brouers-Sotolongo fractal BSf $(n, \alpha)$ kinetic model $\left(\alpha\right.$ and $\left.\tau_{C}\right)$ on the one hand, and of the generalised Brouers-Sotolongo GBS isotherm model ( $a$ and $b$ ) on the other hand, are correlated with adsorption $\mathrm{pH}$ and temperature. For that purpose, adsorption of aqueous solutions of two common dyes, methylene blue (MB) and methyl orange (MO) was carried out on four activated carbons (ACs) at three temperatures $\left(25,35\right.$ and $\left.50^{\circ} \mathrm{C}\right)$ and three $\mathrm{pH}$ (2.5, 5 and 8). Adsorption kinetics and isotherms were measured, and the corresponding curves were best fitted with specific forms of the aforementioned models, and corresponding to equations known as $\mathrm{BSf}(1, \alpha)$ kinetic and Brouers-Gaspard isotherm models. Correlations between all models parameters and adsorption conditions were found, bringing some information about the adsorbate-adsorbent interaction.
\end{abstract}

Keywords: Adsorption; activated carbon; dyes; fractal kinetics; Brouers-Gaspard isotherm; heterogeneous surface 


\section{Introduction}

Adsorption is a complex process that can combine interactions of different physical and/or chemical natures between the adsorbate (solute) and the active sites of the adsorbent, including electrostatic forces and Van der Waals interactions, ligand exchange, hydrogen bounding, or hydrophobic interactions (Volesky 2007). In order to understand the adsorption phenomena, several kinetic and isotherm models have been applied. Concerning kinetics, the most well-known models are intraparticle diffusion (Weber and Morris 1963), pseudo-first order (Lagergren 1898), pseudo-second-order (Ho and McKay 1999) and Elovich (Wu et al. 2009) models. As for adsorption, Freundlich (Freundlich 1906), Langmuir (Langmuir 1918), Sips (Sips 1948) and Temkin (Temkin 1941) isotherm expressions are among the most frequently used.

However, these conventional models are based on unrealistic assumptions, such as monolayer or multilayer adsorption, one single molecule per active site, no interaction between adsorbed molecules, etc., and sometimes they give little information on the adsorbate-adsorbent system. Experimental studies by Kopelman et al. (Klymko and Kopelman 1982; Kopelman 1986) on the kinetic reaction of excitons in molecular macroclusters (inside crystalline isotopic alloy) prepared in fractal form have shown that the rate constant depends on time, which is not expressed in classical models.

For this reason, Kopelman (Kopelman 1988) and Meilanov et al. (Meilanov et al. 2002) expressed the need of developing new kinetic and isotherm models taking into accounts the fractal porosity and the heterogeneity of adsorbate-adsorbent systems. This new approach was developed by Brouers and collaborators. In 2006, Brouers and Sotolongo-Costa (Brouers and Sotolongo-Costa 2006) developed a new kinetic fractal model called BSf $(n, \alpha)$ based on Hill (Jones et al. 2014), Weibull (Tonkin et al. 2014) and Tsallis (Sotolongo-Grau. O et al. 2010; Sotolongo-Grau. O et al. 2013) kinetic formulae, and taking into account the systems 
fractality by using the probability function and the notion of fractional derivative (Pereira 2010). BSf $(n, \alpha)$ encompasses several other models, depending on the values of the parameters $n$ and $\alpha$. This new fractal kinetic model was applied to pharmacokinetics (Pereira 2010), water treatment (Ben Hamissa et al. 2013), and is presently more and more employed (Al-Musawi et al. 2017; Gaspard et al. 2006; Sandro et al. 2009; Selmi et al. 2018c).

In terms of adsorption at equilibrium, Brouers et al. (Brouers et al. 2005) developed a new stochastic model called general Brouers-Sotolongo (GBS) isotherm, which is based on an empirical isotherm using Burr distribution (I.W Burr 1942; Mohan D. Pant and Headrick 2013), Weibull distribution (Tonkin et al. 2014), and a cumulative probability distribution. Brouers extended the empirical model of Langmuir to simple Brouers-Sotolongo (BS) isotherm and generalised the BS model by replacing the exponent in the Weibull function by a deformed exponential used in the formalism of non extensive thermodynamics (Robledo and Moyano 2008; Tsallis 2009). The GBS isotherm also encompasses several other models, depending on the value of its parameters $c$ and $a$, and has become increasingly employed in several domains such as medical application using bacteriophages for the optimised capture of bacteria (Naidoo et al. 2012), water treatment, and adsorption in general (Brouers and AlMusawi 2015; Ncibi et al. 2008; Ncibi and Mika 2015).

Applying the BSf and GBS models presents many advantages compared to traditional ones as they give valuable information on the adsorbent surface and on the adsorbate/adsorbent interface. The main issue is that there is little information on the parameters of BSf and GBS models. In a previous manuscript (Selmi et al. 2018c), these parameters were determined and their relationships with the physicochemical characteristics of four ACs: F200, F300, Acticarbone ${ }^{\circledR}$ and Cecalite ${ }^{\circledR}$ were clarified. The objective of the present study was to elucidate whether there is a correlation between the aforementioned parameters and $\mathrm{pH}$ and 
temperature when studying the adsorption of two dyes: methylene blue (MB) and methyl orange (MO) onto the same ACs.

\section{Experimental}

\subsection{Materials}

Four activated carbons (ACs) were used: Filtrasorb 200 (F200) and Filtrasorb 300 (F300) from Calgon Cooperation, and Acticarbone ${ }^{\circledR}$ and Cecalite ${ }^{\circledR}$ from $C E C A$. Complete details about those materials ACs can be found elsewhere (Selmi et al. 2018c), whereas their main relevant physicochemical characteristics, i.e., those having an effect on adsorption, are reported in Table 1. MB and MO dyes were provided by Sigma-Aldrich (purity > 85\%).

Table 1 : Characteristics of the four ACs used herein (Selmi et al. 2018c): surface area $\left(S_{B E T}\right)$, total pore volume measured by nitrogen adsorption at $-196^{\circ} \mathrm{C}\left(V_{t o t}\right)$, total amount of surface functional groups, and $\mathrm{pH}$ at the point of zero charge $\left(\mathrm{pH}_{P Z C}\right)$.

\begin{tabular}{lcccc}
\hline Activated carbon & F200 & F300 & Acticarbone ${ }^{\circledR}$ & Cecalite ${ }^{\circledR}$ \\
\hline \hline$S_{B E T}\left(\mathrm{~m}^{2} / \mathrm{g}\right)$ & 795 & 884 & 1014 & 582 \\
\hline$V_{\text {tot }}\left(\mathrm{cm}^{3} / \mathrm{g}\right)$ & 0.39 & 0.43 & 0.56 & 0.24 \\
\hline $\begin{array}{l}\text { Total amount of surface } \\
\text { functional groups }(\mathrm{mmol} / \mathrm{g})\end{array}$ & 1.145 & 0.605 & 1.150 & 0.787 \\
\hline$p H_{P Z C}$ & 7.20 & 8.03 & 7.36 & 7.75 \\
\hline
\end{tabular}

\subsection{Adsorption studies}

$\mathrm{MB}$ and MO adsorption kinetics and equilibrium isotherms were performed in batch experiments as follows: $0.3 \mathrm{~g}$ of $\mathrm{AC}$ adsorbent, used in granular form with a grain size not exceeding $1 \mathrm{~mm}$, were added to $100 \mathrm{~mL}$ of $\mathrm{MB}$ or $\mathrm{MO}$ solution with the desired dye 
concentration $(0.5-80 \mathrm{mg} / \mathrm{L})$. The initial $\mathrm{pH}$ was adjusted by adding of $\mathrm{HCl}(0.1 \mathrm{~mol} / \mathrm{L})$ or $\mathrm{NaOH}(0.1 \mathrm{~mol} / \mathrm{L})$ solution, and was measured using a $\mathrm{pH}$ meter ( $p H 315 i$, PROLABMAS). The AC suspensions in dye solutions were stirred magnetically and, after a given time, a sample of $4 \mathrm{~mL}$ was withdrawn and the residual dye concentration was determined with a UV-Vis spectrophotometer (Perkin-Elmer Lambda 35) at a wavelength of $663 \mathrm{~nm}$ for MB, and $464 \mathrm{~nm}$ for MO. Once the absorbance was measured, the liquid sample was put back into the flask in order to maintain a constant liquid volume. The amount of adsorbed dye at equilibrium, $q_{e}(\mathrm{mg} / \mathrm{g})$, was calculated by:

$$
q_{e}=\frac{\left(C_{0}-C_{e}\right) V}{m}
$$

Equation 1

where $C_{0}$ and $C_{e}(\mathrm{mg} / \mathrm{L})$ are the initial and equilibrium dye concentrations, respectively, $V(\mathrm{~L})$ is the volume of solution, and $m(\mathrm{~g})$ is the mass of $\mathrm{AC}$.

Dyes adsorption thermodynamics parameters such as standard entropy $\Delta S^{\circ}$, enthalpy $\Delta H^{\circ}$, and free energy $\Delta G^{\circ}$ were calculated from adsorption data at three temperatures: 25, 35 and $50^{\circ} \mathrm{C}$, using a thermostatic bath regulated at $\pm 1^{\circ} \mathrm{C}$ and following the method reported in detail elsewhere (Enaime et al. 2017).

\subsection{Brouers-Sotolongo kinetic (BSf) and adsorption equilibrium (GBS) models}

The Brouers-Sotolongo fractal kinetic (BSf) model takes into account the adsorption process complexity (Brouers 2014a) and reads:

$$
q_{n, \alpha}(t)=q_{e}\left[1-\left(1+(n-1)\left(\frac{t}{\tau_{C}}\right)^{\alpha}\right)^{\frac{-1}{(n-1)}}\right]
$$

Equation 2

where $\alpha$ is the fractal time exponent, which is a measure of the average energy and width of the adsorption energy distribution; it decreases when the average energy and the width of the energy distribution increase. $n$ is a (possibly fractional, i.e., non-integer) reaction order, and 
$q_{n, \alpha}(t)$ and $q_{e}$ are the adsorbed amounts at any time $t$ and at saturation, respectively. $\tau_{C}$ is the characteristic time of the complex kinetics, and corresponds to the necessary time to reach equilibrium so that the $\mathrm{BSf}$ model can predict the equilibrium time. In relation to the parameters $n, \alpha$ and $\tau_{C}$, a time of half-reaction $\tau_{1 / 2}$ can be determined to predict the time necessary to sorb half of the amount at equilibrium; more details are given elsewhere (Selmi et al. 2018c). Several other models can be recovered from the expression of BSf, depending on the values of $n$ and $\alpha$, as shown in Table 2. More details can be found elsewhere (Brouers 2014a).

Table 2: Kinetic models derived from the BSf kinetic model

\begin{tabular}{cccccc}
\hline$n$ & $\alpha$ & Model & Expression & Eq. number & Reference \\
\hline \hline 1 & 1 & $\begin{array}{c}\text { pseudo-first } \\
\text { order (PFO) }\end{array}$ & $q_{1,1}(t)=q_{e, P F O}\left[1-\operatorname{Exp}\left(-\frac{t}{\tau_{C}}\right)\right]$ & Eq. 3 & (Lagergren 1898) \\
\hline 2 & 1 & $\begin{array}{c}\text { pseudo-second } \\
\text { order (PSO) }\end{array}$ & $q_{2,1}(t)=q_{e, P S O}\left[\frac{t}{\tau_{C}}\right]$ & Eq. 4 & (Ho and McKay \\
& & Weibull & $q_{1, \alpha}(t)=q_{e, W}\left[1-\operatorname{Exp}\left(-\left(\frac{t}{\tau_{C}}\right)^{\alpha}\right)\right]$ & Eq. 5 & (Brouers 2014a) \\
\hline 1 & -- & Hill & $q_{2, \alpha}(t)=q_{e, H}\left[1-\left(1+\left(\frac{t}{\tau_{c}}\right)^{\alpha}\right)^{-1}\right]$ & Eq. 6 & (Brouers 2014a) \\
\hline 2 & -- & & &
\end{tabular}

The GBS isotherm model takes into account the physical and chemical heterogeneity of the adsorbent and of the adsorbate/adsorbent system (Brouers and Al-Musawi 2015). It reads:

$$
q_{e G B S}=q_{e \max }\left[1-\operatorname{Exp}_{c}\left(-\left(\frac{C_{e}}{b}\right)^{a}\right)\right]=q_{e \max }\left[1-\left(1+c\left(\frac{C_{e}}{b}\right)^{a}\right)^{-1 / c}\right] \quad \text { Equation } 7
$$

Depending on the parameters $a$ and $c$, several other models can be derived from the GBS equation, as shown in Table 3; more details can be found elsewhere (Brouers 2014b). 
Table 3: Adsorption isotherms models derived from the GBS isotherm.

\begin{tabular}{cccccc}
\hline$c$ & $a$ & Model & Equation form & Eq. number & Reference \\
\hline \hline 0 & -- & BS & $q_{e B S}=q_{\text {e } \max B S}\left[1-\operatorname{Exp}\left(-\left(\frac{C_{e}}{b}\right)^{a}\right)\right]$ & Eq. 8 & (Brouers 2014b) \\
\hline 0.5 & -- & BG & $q_{e B G}=q_{\text {e } \operatorname{maxBG}}\left[1-\left(1+\frac{1}{2}\left(\frac{C e}{b}\right)^{a}\right)^{-2}\right]$ & Eq. 9 & $\begin{array}{c}\text { (Brouers and Al- } \\
\text { Musawi 2015) }\end{array}$ \\
\hline 1 & -- & HS & $q_{e H S}=q_{\text {e } \operatorname{maxHS}}\left[1-\left(1+\left(\frac{C_{e}}{b}\right)^{a}\right)^{-1}\right]$ & Eq. 10 & (Sips 1948) \\
\hline 1 & 1 & Langmuir & $q_{e L}=q_{e \max L} \frac{C_{e}}{b+C_{e}}$ & Eq. 11 & (Langmuir 1918) \\
\hline$C_{e}<<b$ & Freundlich & $q_{e F}=K_{F} C_{e}^{a}$ & Eq. 12 & (Freundlich 1906) \\
\hline
\end{tabular}

The experimental data were non-linearly fitted by using the Levenberg-Marquardt iteration algorithm supplied with OriginPro® 2016 Software.

\section{Results and discussion}

\subsection{Effect of initial dye concentration on adsorption kinetics}

Figure 1 shows the effect of the initial concentration of MB (Fig. 1(a)) and of MO (Fig. 1(b)) on the time required for reaching the equilibrium, which increased with the initial dye concentration. As can be seen, adsorption occurred in two stages: (i) the initial adsorption stage was fast, probably due to the high number of sites available for sorption; (ii) the second phase was slower due to the fact that the number of easily accessible sites decreased and the adsorbate needed longer times to reach the last remaining adsorption sites (Kesraoui et al. 2016). As an example, the necessary time to reach the equilibrium on F300 was 50 min and $25 \mathrm{~min}$ when using $C_{0}=5 \mathrm{mg} / \mathrm{L}$ of $\mathrm{MB}$ and $\mathrm{MO}$, respectively. The equilibrium time was multiplied by a factor 4 when increasing the initial dye concentration up to $80 \mathrm{mg} / \mathrm{L}$, suggesting that adsorption was controlled by intraparticle and boundary layer diffusion 
(Enaime et al. 2017). Similar results were found with the other 3 ACs (see Figures SI 1 to SI 3 of the Supplementary Information).
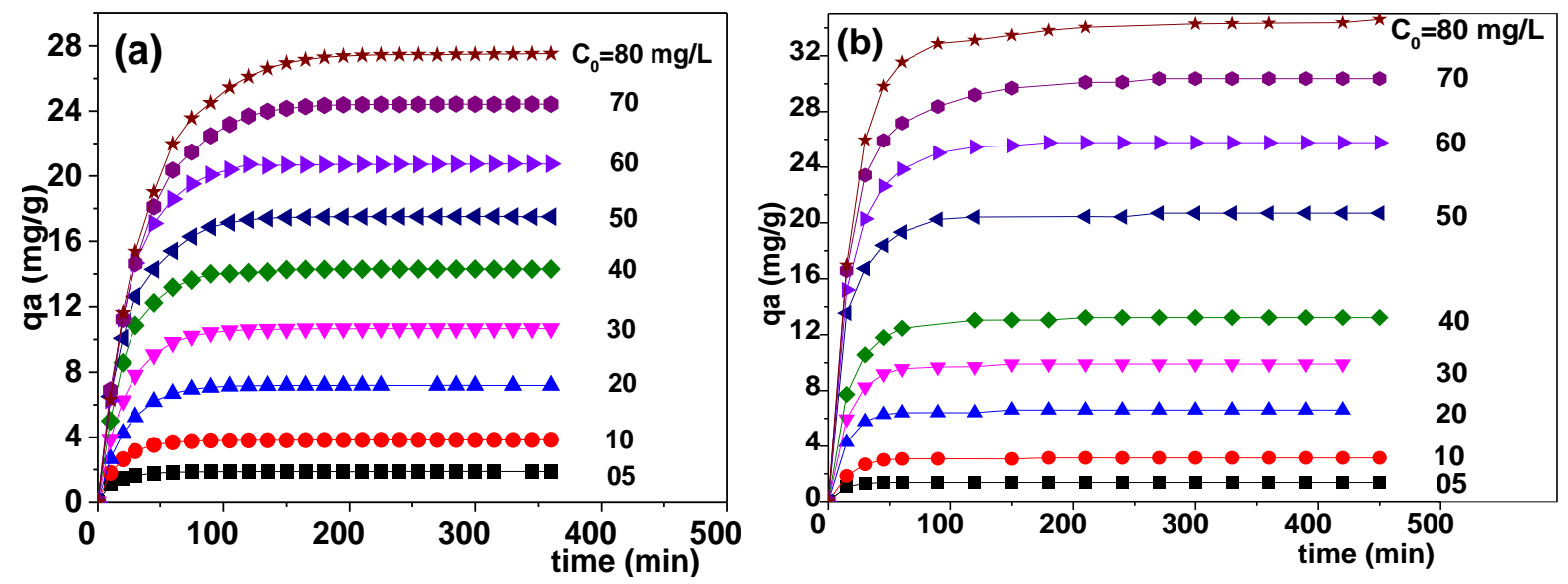

Figure 1: Effect of contact time and initial concentration on: (a) $\mathrm{MB}$ at $\mathrm{pH}$ 8; and (b) $\mathrm{MO}$ at $\mathrm{pH} 2.5$ onto $\mathrm{F} 300$ at $25^{\circ} \mathrm{C}$ (lines are just guides for the eye).

\subsection{Effect of initial $\mathrm{pH}$ and temperature on adsorption}

Figure 2 and Table SI 1 shows the effect of $\mathrm{pH}$ and temperature on $\mathrm{MB}$ and $\mathrm{MO}$ adsorption capacities of the four ACs when the initial dye concentration $C_{0}$ was fixed to $10 \mathrm{mg} / \mathrm{L}$. These effects were investigated at $\mathrm{pH} 2.5,5$ and 8 at each temperature of 25,35 and $50^{\circ} \mathrm{C} . \mathrm{MB}$ adsorption at equilibrium onto F300 increased slightly from 3.18 to $3.39 \mathrm{mg} / \mathrm{g}$ when the $\mathrm{pH}$ increased from 2.5 to 8 at $25^{\circ} \mathrm{C}$, indicating that $\mathrm{MB}$ was favourably adsorbed at basic $\mathrm{pH}$. On the contrary, MO adsorption at equilibrium onto F300 decreased slightly from 3.15 to 3.00 $\mathrm{mg} / \mathrm{g}$ when the $\mathrm{pH}$ increased from 2.5 to 8 at $25^{\circ} \mathrm{C}$ indicating that $\mathrm{MO}$ was favourably adsorbed at acidic $\mathrm{pH}$. This fact is in agreement with the $p H_{P Z C}$ of $\mathrm{F} 300$ (8.03), suggesting that the adsorbent surface was approximately neutral at $\mathrm{pH} 8$ and positively charged at $\mathrm{pH} 2.5$, i.e., was attracting anions. $\mathrm{MB}$ is a cationic dye, and hence it is positively charged in solution and thus more adsorbed at basic $\mathrm{pH}$ when the surface of the carbon is not charged, than at 
acidic $\mathrm{pH}$ when the surface of the carbon is positively charged. The opposite was observed for MO, which is an anionic dye.

Therefore, the study of the effect of temperature on adsorption onto was made by fixing the $\mathrm{pH}$ to 8 for $\mathrm{MB}$ and to 2.5 for $\mathrm{MO}$. The amounts of $\mathrm{MB}$ and $\mathrm{MO}$ adsorbed onto F300 increased with temperature from 25 to $50^{\circ} \mathrm{C}$ from 3.39 to $3.84 \mathrm{mg} / \mathrm{g}$ for $\mathrm{MB}$, and from 3.15 to $3.51 \mathrm{mg} / \mathrm{g}$ for MO (Table SI 1). The corresponding data will be examined in terms of thermodynamic parameters in the next section.

Figure 2 shows the $\mathrm{MB}$ and $\mathrm{MO}$ equilibrium adsorption capacities of the four $\mathrm{ACs}$ as a function of temperature and $\mathrm{pH}$. All adsorbents had $p H_{P Z C}$ between 7.20 and 8.03, therefore they essentially had the same behaviour, i.e., MB adsorption was more favourable at $\mathrm{pH} 8$, when the surface of the $\mathrm{AC}$ was nearly neutral, than at $\mathrm{pH} 2.5$, when it was positively charged and thus led to higher electrostatic repulsion. On the contrary, MO adsorption was more favourable at $\mathrm{pH} 2.5$ when surface of $\mathrm{AC}$ was positively charged and thus led to higher electrostatic attraction since MO is an anionic dye. Dissociation and electrostatic repulsion are also largely influenced by temperature (Ncibi and Mika 2015), and the same general trend was observed for the four ACs. Adsorption increased with temperature in the range 35 to $50^{\circ} \mathrm{C}$.
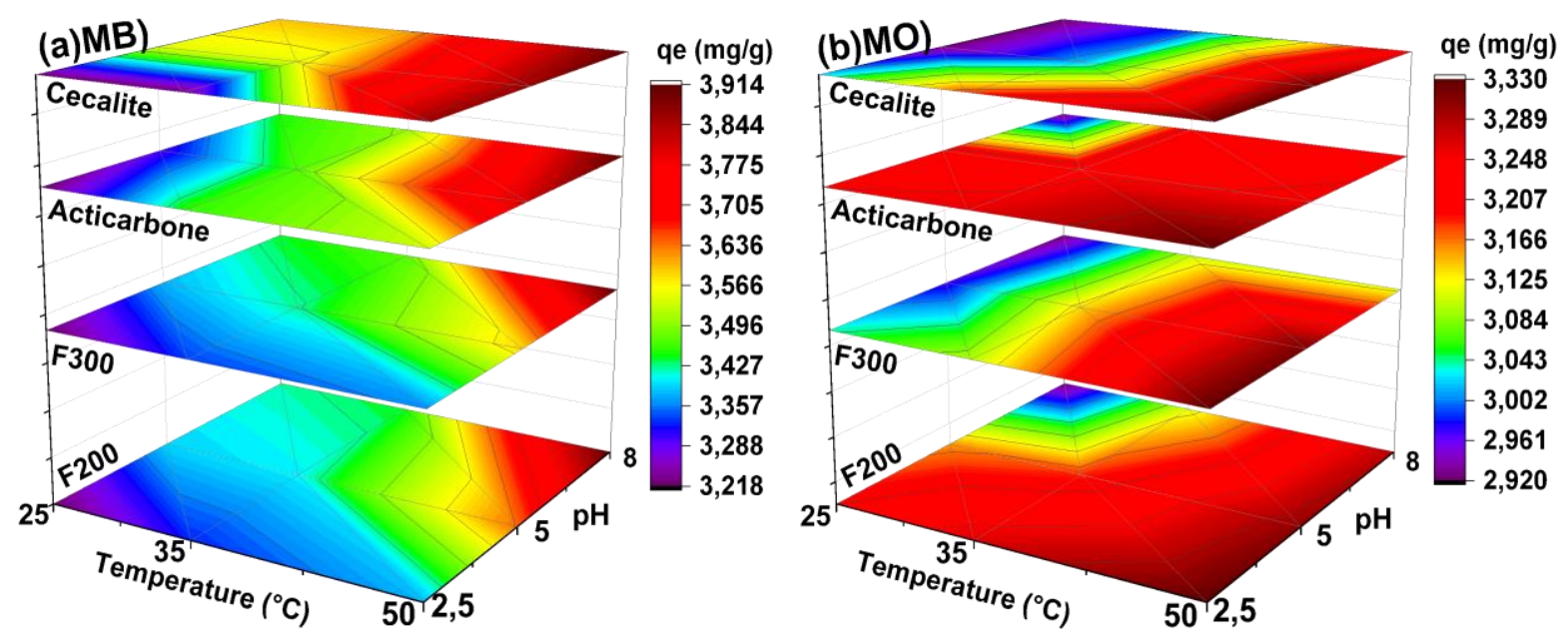
Figure 2: Effect of $\mathrm{pH}$ and temperature on the adsorbed amount onto ACs of: (a) MB; and (b) $\mathrm{MO}$, both at $C_{0}=10 \mathrm{mg} / \mathrm{L}$.

\subsection{Thermodynamic analysis}

Figure 3 shows the variation of standard free energy $\Delta G^{\circ}$ with $\mathrm{pH}$ and temperature for $\mathrm{MB}$ and $\mathrm{MO}$ adsorption onto the four ACs. $\Delta G^{\circ}$ was in the range from -6.00 to $-20.45 \mathrm{~kJ} / \mathrm{mol}$, indicating the spontaneous nature of $\mathrm{MB}$ and $\mathrm{MO}$ adsorption onto the four materials. The absolute value of $\Delta G^{\circ}$ increased with temperature, for all $\mathrm{pH}$, indicating a more efficient adsorption at higher temperature. Apart from this, the absolute value of $\Delta G^{\circ}$ decreased with an increase of $\mathrm{pH}$ for $\mathrm{MB}$ adsorption, whereas the opposite occurred with $\mathrm{MO}$. This behaviour was clearly seen for MB adsorption at the highest temperature, but was less obvious for MO adsorption in the same conditions due to the opposite effects of $\mathrm{pH}$ and temperature on $\mathrm{MO}$ adsorption.
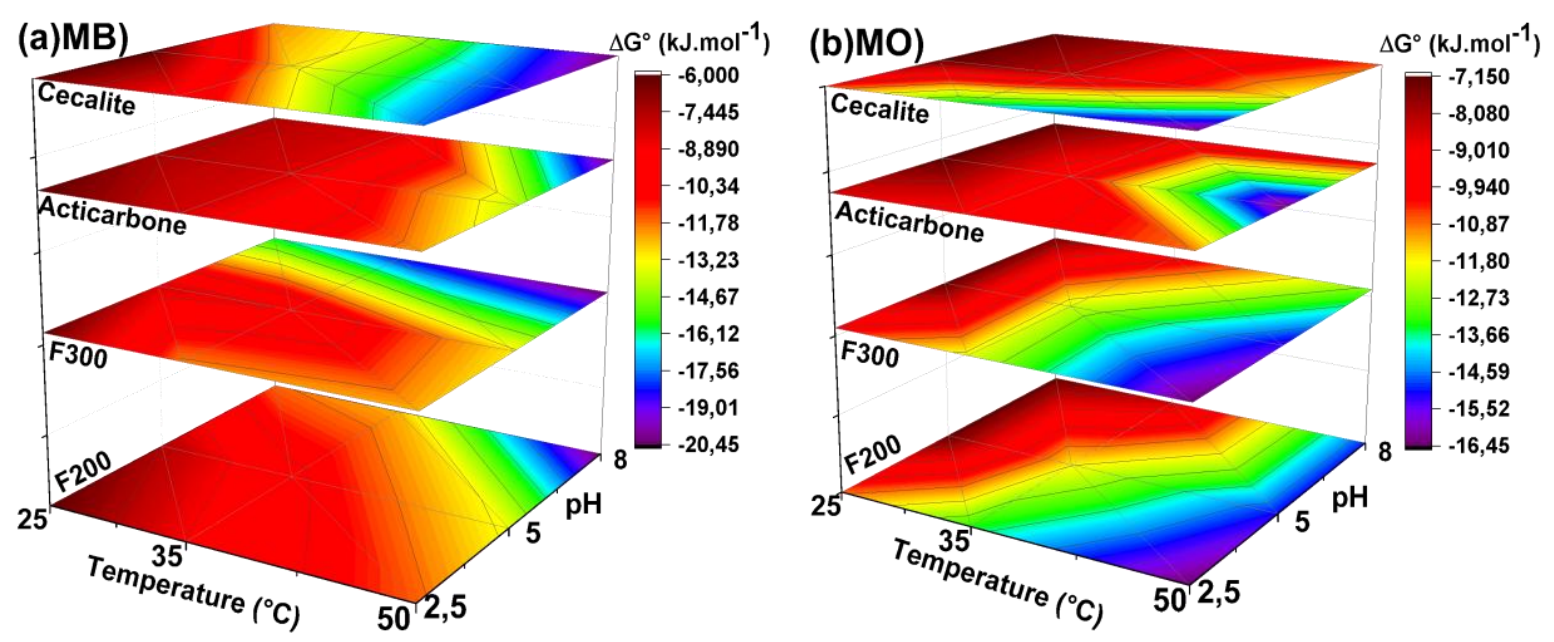

Figure 3: Effect of $\mathrm{pH}$ and temperature on the free energy of adsorption $\Delta G^{\circ}$ onto the four ACs of: (a) MB; and (b) MO, both at $C_{0}=10 \mathrm{mg} / \mathrm{L}$.

Figure 4 shows the variations of standard adsorption enthalpy $\Delta H^{\circ}$ and of standard adsorption entropy $\Delta S^{\circ}$ with $\mathrm{pH}$ for $\mathrm{MB}$ and $\mathrm{MO}$ adsorption onto the four ACs; the 
corresponding numerical results are given in Table SI 2 of the Supplementary Information. $\Delta H^{\circ}$ was always positive: it decreased when the $\mathrm{pH}$ was increased for the adsorption of $\mathrm{MB}$, but increased with $\mathrm{pH}$ for the adsorption of MO onto all ACs (Figure 4 and Table SI 2 of the Supplementary Information).

$\Delta S^{\circ}$ was always positive and showed the same behaviour as $\Delta H^{\circ}$ with $\mathrm{pH}$ (Figure 4 and Table SI 2 of the Supplementary Information). The positive values of $\Delta S^{\circ}$ suggest an increased randomness at the AC/solution interface during the sorption process. Similar results were found by other investigators working on dye adsorption onto various adsorbents (Bouhamed et al. 2016; Enaime et al. 2017; Kesraoui et al. 2017; Selmi et al. 2018a).
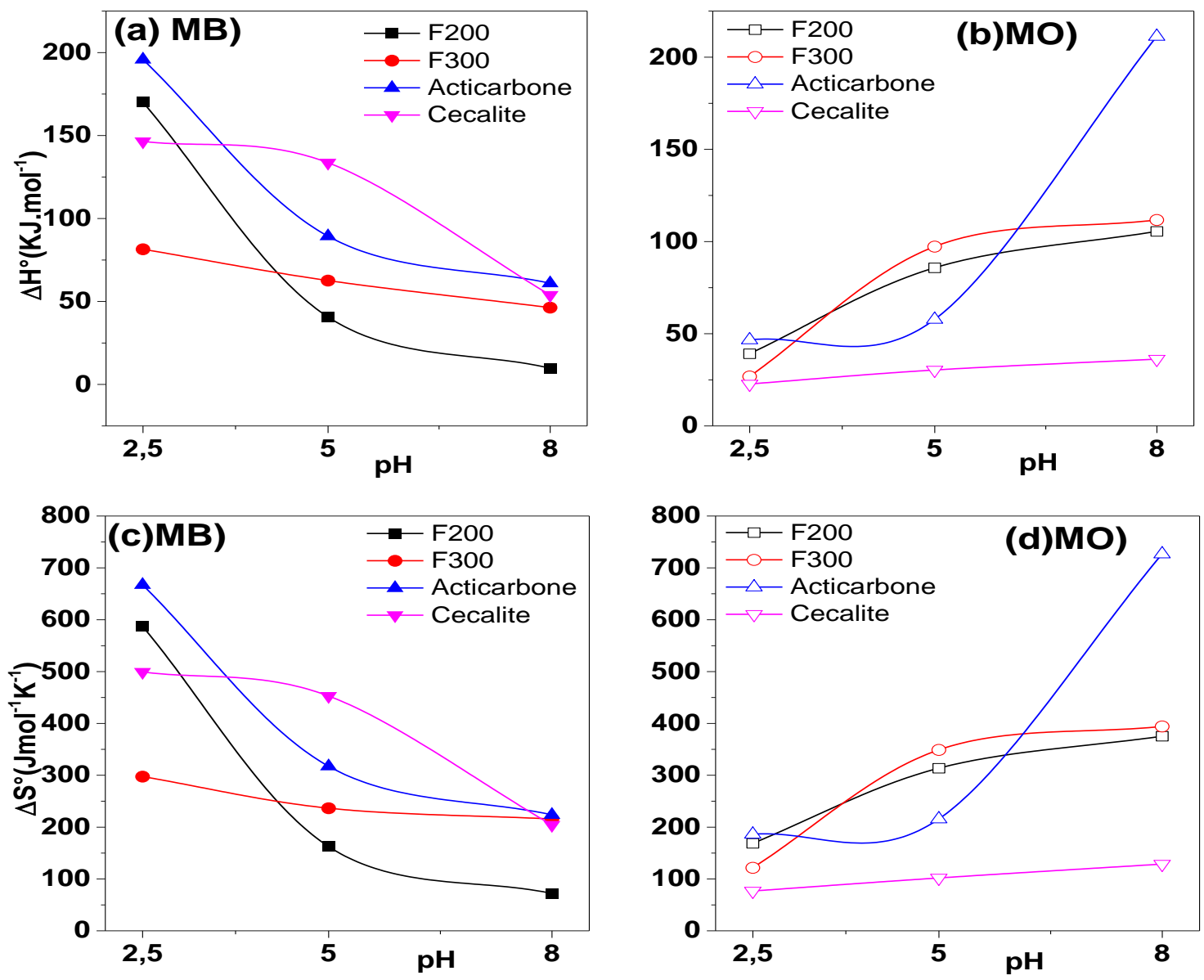

Figure 4: Effect of $\mathrm{pH}$ on: ( $\mathrm{a}$ and b) standard adsorption enthalpy $\Delta H^{\circ}$; and (c and d) on standard adsorption entropy $\Delta S^{\circ}$ for: (a and c) MB; and (b and) MO onto the four ACs. 


\subsection{Kinetic data analysis}

Herein, based on our former work (Selmi et al. 2018c), the reaction order $n=1$ was used for the BSf kinetics model because of the excellent fits it let for all ACs. The Weibull equation ( $n=1$ and $\alpha \neq 1$ ) was indeed the most relevant one for fitting the kinetic data, and this was in agreement also with previous studies on Indigo Carmine adsorption onto F200 (Kesraoui et al. 2017). Figure 5 shows the experimental kinetic data of MB and MO adsorption onto F300, and the corresponding non-linear fits using the BSf $(1, \alpha)$ model (i.e., $n$ was fixed to 1$)$. The $\operatorname{BSf}(1, \alpha)$ model fitted very well the experimental data and equally good results were obtained for the other three ACs, as shown in Figure SI 4 of the Supplementary Information.
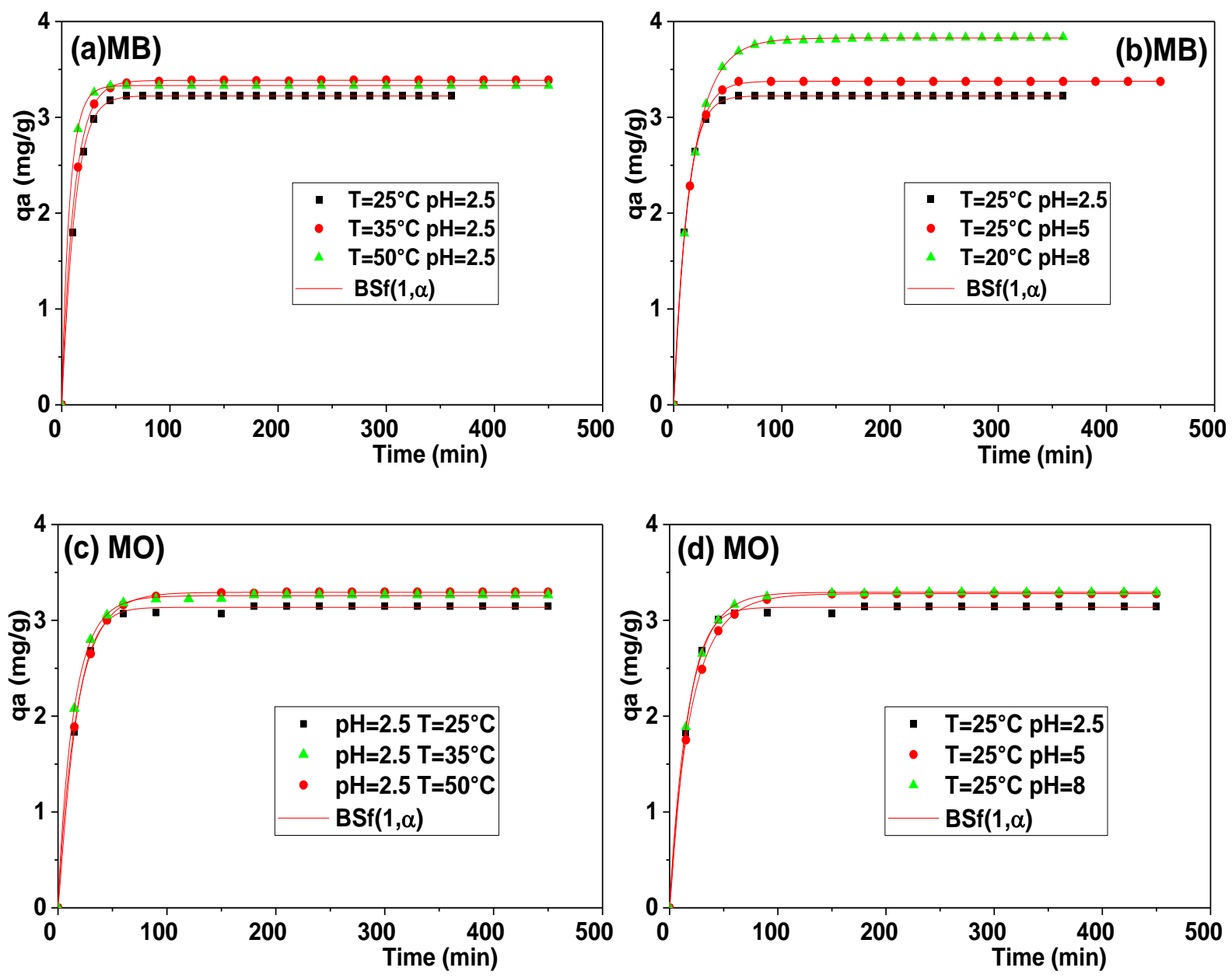
Figure 5: BSf $(1, \alpha)$ kinetics model applied to the adsorption of: $(a, b) \mathrm{MB}$; and (c,d) MO onto F300 for different $\mathrm{pH}$ and temperatures, using an initial dye concentration $C_{0}=10 \mathrm{mg} / \mathrm{L}$.

Figure 6 shows the effect of $\mathrm{pH}$ and temperature on the BSf $(1, \alpha)$ constants $\tau_{C}$ and $\alpha$ for the adsorption of $\mathrm{MB}$ and $\mathrm{MO}$. Certain correlations between $\tau_{C}, \alpha_{\mathrm{MB}}, \alpha_{\mathrm{MO}}$ with $\mathrm{pH}$ and temperature were observed. Tables SI 3 to SI 6 of the Supplementary Information present the BSf $(1, \alpha)$ parameters for the four ACs.

Previous studies (Al-Musawi et al. 2017; Ben Hamissa et al. 2013; Selmi et al. 2018b; Selmi et al. 2018c) showed that the interactions between adsorbate/adsorbent were fractal when $\alpha$, sometimes referred to as the global fractal time, was lower than $1 . \alpha$ represents the memory effect produced in systems where the reaction at any time, $t$, depends on the history of the process. $\alpha$ arises from the energetic and geometric heterogeneity of the adsorbent (Ben Hamissa et al. 2013). Figure 6(b) and Table SI 3 of the Supplementary Information show that the adsorption of MB onto F300 is slightly fractal ( $\alpha_{\mathrm{MB}}$ between 0.80 and 1.12) and the adsorption of MO onto F300 is clearly fractal ( $\alpha_{\mathrm{MO}}$ between 0.67 and 1.13 ). On the one hand, $\alpha_{\mathrm{MB}}$ increased from 0.92 to 1.07 when the $\mathrm{pH}$ was increased from 2.5 to 8 at $25^{\circ} \mathrm{C}$, indicating that raising the $\mathrm{pH}$ diminished the fractal nature of the phenomena. On the other hand, $\alpha_{\mathrm{MO}}$ decreased from 1.13 to 0.92 when increasing the $\mathrm{pH}$ from 2.5 to 8 at $25^{\circ} \mathrm{C}$, indicating that, instead, raising the $\mathrm{pH}$ promoted fractal adsorption of $\mathrm{MO}$ onto F300. In fact, fractal phenomena became stronger when increasing the $\mathrm{pH}$ at temperatures above $35^{\circ} \mathrm{C}$ for both $\mathrm{MB}$ and MO adsorption. The same results were found when studying MB adsorption onto F200 and Acticarbone ${ }^{\circledR}$, and MO adsorption onto Acticarbone ${ }^{\circledR}$ and onto Cecalite ${ }^{\circledR}$ (see Figure SI 5 and Tables SI 4 and SI 5 of the Supplementary Information). MB adsorption onto Cecalite ${ }^{\circledR}$ deserves special attention because it is highly fractal, with a $\alpha_{\mathrm{MB}}$ around 0.67 on average; see Figure SI 5 and Table SI 6 of the Supplementary Information. 
Since the increase of $\mathrm{pH}$ had a positive effect on the adsorption of $\mathrm{MB}$ and a negative effect on the adsorption of $\mathrm{MO}$, the characteristic time decreased with $\mathrm{pH}$ for $\mathrm{MB}$ adsorption (e.g. from 16.69 to $12.14 \mathrm{~min}$ at $25^{\circ} \mathrm{C}$ for $\mathrm{MB}$ adsorption onto $\mathrm{F} 300$ ), and increased with $\mathrm{pH}$ for $\mathrm{MO}$ adsorption (e.g. from 16.78 to $20.16 \mathrm{~min}$ at $25^{\circ} \mathrm{C}$ for $\mathrm{MO}$ adsorption onto $\mathrm{F} 300$ ). The same behaviour was clearly apparent for the adsorption of $\mathrm{MB}$ and $\mathrm{MO}$ onto all other ACs (see Figure 6, and Figure SI 5 and Tables SI 3 to SI 6 of the Supplementary Information).

On the other hand, the temperature had a positive effect on both MB and MO adsorption, the increase of temperature increasing the initial rate of dye adsorption. Consequently, the characteristic time decreased with temperature. This behaviour is clearly apparent for the adsorption of MB and MO onto all ACs in Figure 6, Figure SI 5, and Tables SI 3 to SI 6 of the Supplementary Information. At favourable $\mathrm{pH}$ (8 for $\mathrm{MB}$ and 2.5 for $\mathrm{MO}$ ), the characteristic time for the adsorption onto $\mathrm{F} 300$ of $\mathrm{MB}, \tau_{c M B}$, and of $\mathrm{MO}, \tau_{c M O}$, decreased when increasing the temperature, from 12.14 to $6.23 \mathrm{~min}$ and from 16.78 to $8.25 \mathrm{~min}$, respectively (see Table SI 3 of the Supplementary Information). These results agree with previous studies (Ben Hamissa et al. 2013; Kesraoui et al. 2017; Selmi et al. 2018b). Increasing $\mathrm{pH}$ and temperature at the same time produced a decrease of the fractality degree $\alpha$ and the adsorption became faster, reducing in turn the characteristic time, $\tau_{C}$.)
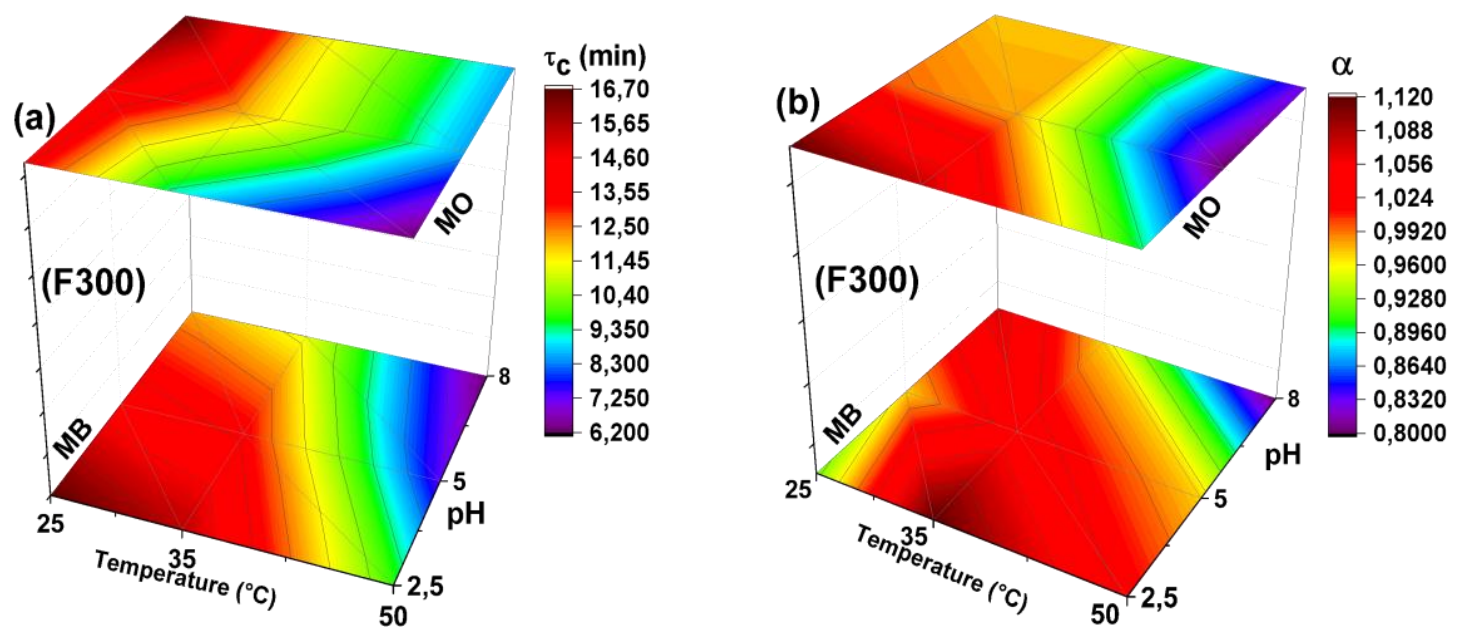

Figure 6: Variation with $\mathrm{pH}$ and temperature of $\operatorname{BSf}(1, \alpha)$ parameters: (a) $\tau_{C}$; and (b) $\alpha$, for the adsorption onto F300 of MB and MO (both at $C_{0}=10 \mathrm{mg} / \mathrm{L}$ ). 


\subsection{Adsorption isotherm fitting}

The GBS isotherm was used by fixing the heterogeneity degree, $c$, equal to 0.5 , based on a previous study (Selmi et al. 2018c). And indeed, excellent fits were obtained with $c=0.5$, hence the Brouers-Gaspard (BG) equation $(a \neq 1$ and $c=0.5)$ was the most relevant one for fitting the isotherm adsorption data of $\mathrm{MB}$ and $\mathrm{MO}$ onto ACs. A stochastic analysis of physicochemical reactions in complex systems (Stanislavsky and Weron 2013) showed that the exponent $c$ is related to the cluster or aggregation organization of the system. Figure 7 shows that the experimental isotherms of MB and MO adsorbed onto F300 were very well fitted with BG equation. Equally good results were obtained for the other three ACs, and the corresponding results are given in Figure SI 6 of the Supplementary Information.
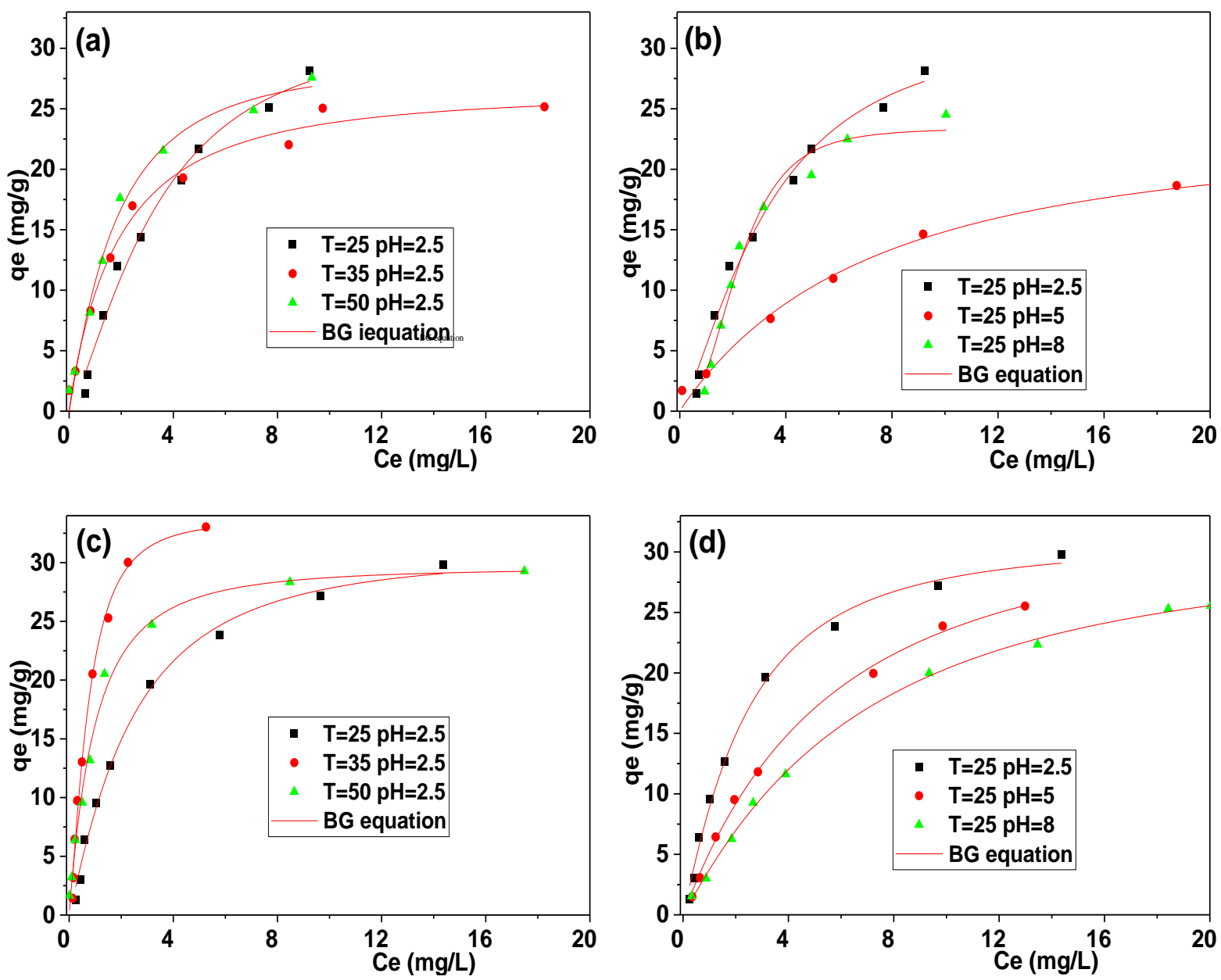
Figure 7: Fits of the BG isotherm to the adsorption data onto F300 of: (a and b) MB; and (c and d) $\mathrm{MO}$, for different temperatures and $\mathrm{pH}$.

Figure 8 shows the effect of $\mathrm{pH}$ and temperature on the BG parameters $a$ and $b$ for the adsorption of $\mathrm{MB}$ and $\mathrm{MO}$, obtained from the non-linear fits of the adsorption data for all ACs. The corresponding values are listed in Tables SI 7 to SI 10 of the Supplementary Information. $a$ and $b$ are clearly correlated with $\mathrm{pH}$ and temperature. For instance, $a$ increased with $\mathrm{pH}$ (from 0.48 to 0.93 at $25^{\circ} \mathrm{C}$ ) and temperature (from 0.93 to 2.15 at $\mathrm{pH}$ 8), see Table SI 7, for MB adsorption onto F300. On the other hand, $a$ decreased when increasing the $\mathrm{pH}$ from 2.5 to 8 (from 1.06 to 0.98 at $25^{\circ} \mathrm{C}$ ) for $\mathrm{MO}$ adsorption onto $\mathrm{F} 300$, and increased with temperature from 25 to $50^{\circ} \mathrm{C}$ (from 1.06 to 1.26 at $\mathrm{pH} 2.5$ ) due to the unfavourable effect of $\mathrm{pH}$ and favourable effect of temperature (Table SI 7). The same behaviours were clearly observed for the adsorption of MB and MO onto the 3 other ACs (Tables SI 8 to SI 10).

BG sorption model assumes that adsorption takes place on a heterogeneous surface with a distribution of sorption energies representative of different active sites which are progressively occupied. $a$ represents a degree of the fractal nature of a heterogeneous system (Brouers 2014a; Brouers and Al-Musawi 2015; Brouers and Francisco 2016). When $a>1$, fast initial sorption kinetics occurs, and there is probably more than one molecule sorbed by active site; when $a<1$, slow initial sorption kinetics is observed. Brouers et al. (Brouers et al. 2005 ) showed that the exponent $a$ is proportional to $k T / E_{s}$, where $k, T$ and $E_{s}$ are Boltzmann constant, absolute temperature and sorption energy distribution, respectively. For a typical $E_{s}$, $1 / \alpha$ measures the energy distribution width, and therefore the energy heterogeneity of the surface.

The parameter $b$ was also correlated with $\mathrm{pH}$ and temperature. At $25^{\circ} \mathrm{C}$, the values of $b$ related to $\mathrm{MB}$ and $\mathrm{MO}$ adsorption onto $\mathrm{F} 300$ decreased from 3.49 to $2.37 \mathrm{mg} / \mathrm{L}$ and increased from 2.49 to $8.74 \mathrm{mg} / \mathrm{L}$, respectively, when increasing the $\mathrm{pH}$ from 2.5 to 8 . At favourable $\mathrm{pH}$ 
( 8 for $\mathrm{MB}$ and 2.5 for $\mathrm{MO}$ ), the $b$ parameter of $\mathrm{MB}$ and $\mathrm{MO}$ adsorption onto $\mathrm{F} 300$ decreased from 2.37 to $0.20 \mathrm{mg} / \mathrm{L}$ and from 2.49 to $0.79 \mathrm{mg} / \mathrm{L}$, respectively, when increasing the temperature from 25 to $50^{\circ} \mathrm{C}$. Similar results were clearly observed for the adsorption of MB and MO onto the other three ACs (see again Tables SI 8 to SI 10 of the Supplementary Information). The increase of temperature speeds up the adsorption, so that the isotherm reaches quickly at saturation and thereafter the equilibrium concentration decreases. $b$ is thus related to equilibrium concentration, in agreement with previous results (Selmi et al. 2018c).
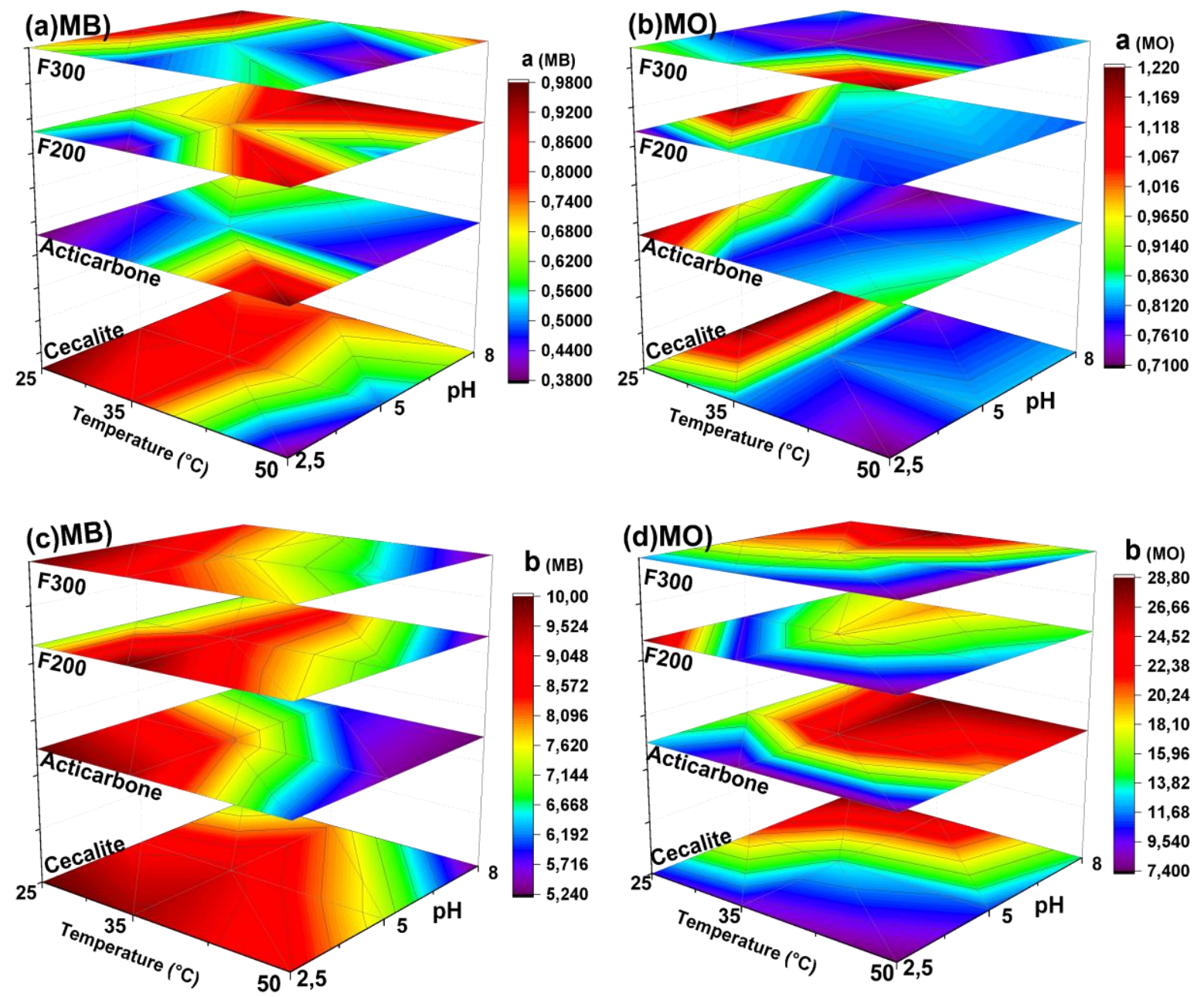

Figure 8: Variation with $\mathrm{pH}$ and temperature of BG parameters, $a$ and $b$, determined by adsorption of: (a and c) MB; (b and d) MO, onto F200, F300, Acticarbone® and Cecalite ${ }^{\circledR}$. 


\section{Conclusion}

In this work, the adsorption of two different dyes in aqueous solution, methylene blue (MB) and methyl orange (MO), was investigated as a function of $\mathrm{pH}$ and temperature on four different activated carbons. The thermodynamics studies revealed that the adsorption process is spontaneous and endothermic. Both the nonlinear Brouers-Sotolongo fractal, BSf $(n, \alpha)$, kinetic model and the generalised Brouers-Sotolongo, GBS, isotherm model were found to fit very adequately the corresponding experimental results.

The experimental kinetic data were best described by the $\operatorname{BSf}(1, \alpha)$ model involving the adsorption of $\mathrm{MB}$ and $\mathrm{MO}$ on a fractal surface of $\mathrm{AC}$. The parameter $\alpha$, named global fractal time index, can be correlated with both $\mathrm{pH}$ and temperature, indicating its effects on the surface fractality and leading to the conclusion that its value comes from the assumed fractal diffusion and sorption kinetics. This is due to the energetic and geometric heterogeneity of the surface of adsorbent. The characteristic time $\tau_{C}$ necessary to reach the equilibrium could also be correlated with both $\mathrm{pH}$ and temperature: the favourable effect of $\mathrm{pH}$ and temperature decreased $\tau_{C}$.

As for the data at equilibrium, the isotherms were best described by the Brouers-Gaspard (BG) model, which involves the adsorption of MB and MO onto a heterogeneous AC surface. The exponent $a$, which measures the energy heterogeneity of the surface, was found to be proportional to the adsorption energy distribution. The favourable effect of both $\mathrm{pH}$ and temperature decreased the constant $b$ of the model, which was found to be related to equilibrium concentration. 


\section{Acknowledgements}

The authors gratefully acknowledges the financial support from the EU-METALIC: Erasmus

Mundus project and the Tunisian Ministry of Higher Education and Scientific Research. 


\section{References}

Al-Musawi TJ, Brouers F, Zarrabi M (2017) Kinetic modeling of antibiotic adsorption onto different nanomaterials using the Brouers-Sotolongo fractal equation Environ Sci Pollut Res 24:4048-4057 doi:10.1007/s11356-016-8182-z

Ben Hamissa AM, Brouers F, Ncibi MC, Seffen M (2013) Kinetic Modeling Study on Methylene Blue Sorption onto Agave americana fibers: Fractal Kinetics and $\begin{array}{lllll}\text { Regeneration } & \text { Studies } & \text { Sep } & \text { Sci } & \text { Technol 2834-2842 }\end{array}$ doi:10.1080/01496395.2013.809104

Bouhamed F, Elouear Z, Bouzid J, Ouddane B (2016) Multi-component adsorption of copper, nickel and zinc from aqueous solutions onto activated carbon prepared from date stones Environ Sci Pollut Res 23:15801-15806 doi:10.1007/s11356-015-4400-3

Brouers F (2014a) The fractal (BSf) kinetics equation and its approximations J Mod Phys 5:1594 doi:doi.org/10.4236/jmp.2014.516160

Brouers F (2014b) Statistical foundation of empirical isotherms Open J Stat 4:687-701 doi:http://dx.doi.org/10.4236/ojs.2014.49064

Brouers F, Al-Musawi TJ (2015) On the optimal use of isotherm models for the characterization of biosorption of lead onto algae $J$ Mol Liq 212:46-51 doi:10.1016/j.molliq.2015.08.054

Brouers F, Francisco M-M (2016) Dubinin isotherms versus the Brouers-Sotolongo family isotherms: A case study Adsor Sci Technol 34:552-564 doi:doi:10.1177/0263617416670909

Brouers F, Sotolongo-Costa O (2006) Generalized fractal kinetics in complex systems (application to biophysics and biotechnology) Phys A: Stat Mech Appl 368:165-175 doi:http://doi.org/10.1016/j.physa.2005.12.062

Brouers F, Sotolongo O, Marquez F, Pirard JP (2005) Microporous and heterogeneous surface adsorption isotherms arising from Levy distributions Phys A: Stat Mech Appl 349:271-282 doi:http://doi.org/10.1016/j.physa.2004.10.032

Enaime G, Ennaciri K, Ounas A, Baçaoui A, Seffen M, Selmi T, Yaacoubi A (2017) Preparation and characterization of activated carbons from olive wastes by physical and chemical activation: Application to Indigo carmine adsorption $\mathrm{J}$ Mater Environ Sci 8:4125-4137

Freundlich H (1906) Over the adsorption in solution J Phys Chem 57:385-471 
Gaspard S, Altenor S, Passe-Coutrin N, Ouensanga A, Brouers F (2006) Parameters from a new kinetic equation to evaluate activated carbons efficiency for water treatment Water Res 40:3467-3477 doi:10.1016/j.watres.2006.07.018

Ho YS, McKay G (1999) Pseudo-second order model for sorption processes Process Biochem 34:451-465 doi:http://doi.org/10.1016/S0032-9592(98)00112-5

I.W Burr (1942) Cumulative Frequency Functions The Annals of Mathematical Statistics 13:215-232 doi:org/10.1214/aoms/1177731607

Jones LB, Secomb TW, Dewhirst MW, El-Kareh AW (2014) The additive damage model: A mathematical model for cellular responses to drug combinations J Theor Biol 357:1020 doi:https://doi.org/10.1016/j.jtbi.2014.04.032

Kesraoui A, Moussa A, Ben Ali G, Seffen M (2016) Biosorption of alpacide blue from aqueous solution by lignocellulosic biomass: Luffa cylindrica fibers Environ Sci Pollut Res 23:15832-15840 doi:10.1007/s11356-015-5262-4

Kesraoui A, Selmi T, Seffen M, Brouers F (2017) Influence of alternating current on the adsorption of indigo carmine Environ Sci Pollut Res 24:9940-9950 doi:10.1007/s11356-016-7201-4

Klymko PW, Kopelman R (1982) Heterogeneous exciton kinetics: triplet naphthalene homofusion in an isotopic mixed crystal The Journal of Physical Chemistry 86:36863688 doi: $10.1021 / \mathrm{j} 100216 \mathrm{a} 003$

Kopelman R (1986) Rate processes on fractals: Theory, simulations, and experiments Journal of Statistical Physics 42:185-200 doi:10.1007/bf01010846

Kopelman R (1988) Fractal Reaction Kinetics Science 241:1620-1626 doi:doi.org/10.1126/science.241.4873.1620

Lagergren S (1898) Zur Theorie der Sogenannten Adsorption Gelöster Stoffe, Kungliga Svenska Vetenskapsakade- miens Handlingar 24:1-39

Langmuir I (1918) The adsorption of gases on plane surfaces of glass, mica, and platinum $\mathbf{J}$ American Chem Society 40:1361

Meilanov RP, D.A Sveshnikova, Shabanov OM (2002) Fractal nature of sorption kinetics J Phys Chem A 106:11771-11774 doi:10.1021/jp0216575

Mohan D. Pant, Headrick TC (2013) A Method for Simulating Burr Type III and Type XII Distributions through L-Moments and L-Correlations Hindawi Publishing Corporation ISRN Applied Mathematics 2013:14 doi:org/10.1155/2013/191604 
Naidoo R et al. (2012) Surface-immobilization of chromatographically purified bacteriophages for the optimized capture of bacteria Bacteriophage 2:15-24 doi:10.4161/bact.19079

Ncibi M, Altenor S, Seffen M, Brouers F, Gaspard S (2008) Modelling single compound adsorption onto porous and non-porous sorbents using a deformed Weibull exponential isotherm Chem Eng J 145:196-202

Ncibi MC, Mika S (2015) Optimized removal of antibiotic drugs from aqueous solutions usingsingle, double and multi-walled carbon nanotubes J Hazard Mater 298:102-110 doi:org/10.1016/j.jhazmat.2015.05.025

Pereira LM (2010) Fractal Pharmacokinetics Comput Math Methods in Med 11:161-184 doi:10.1080/17486700903029280

Robledo A, Moyano LG (2008) q-deformed statistical-mechanical property in the dynamics of trajectories en route to the Feigenbaum attractor Physical Review E 77:036213 doi:10.1103/PhysRevE.77.036213

Sandro A, Betty Carene, Evens Emmanuel, Jacques Lambert, Jean-Jacques Ehrhardt, Gaspard S (2009) Adsorption studies of methylene blue and phenol onto vetiver roots activated carbon prepared by chemical activation J Hazard Mater 165:1029-1039 doi:10.1016/j.jhazmat.2008.10.133

Selmi T et al. (2018a) Tetracycline removal with activated carbons produced by hydrothermal carbonisation of Agave americana fibres and mimosa tannin Ind Crops Prod 115:146157 doi:https://doi.org/10.1016/j.indcrop.2018.02.005

Selmi T, Seffen M, Brouers F, Fierro V, Sammouda H (2018b) Adsorption of Model Dyes Onto Porous Materials: Effect of $\mathrm{pH}$ and Temperature on the Parameters of BrouersSotolongo Kinetic Fractal and Generalized Isotherm. In: Kallel A, Ksibi M, Ben Dhia H, Khélifi N (eds) Recent Advances in Environmental Science from the EuroMediterranean and Surrounding Regions: Proceedings of Euro-Mediterranean Conference for Environmental Integration (EMCEI-1), Tunisia 2017. Springer International Publishing, Cham, pp 1039-1041. doi:10.1007/978-3-319-70548-4_299

Selmi T, Seffen M, Sammouda H, Sandrine M, Jagiello J, Celzard A, Fierro V (2018c) Physical meaning of the parameters used in fractal kinetic and generalised adsorption models of Brouers-Sotolongo Adsorption 24:11-27 doi:10.1007/s10450-017-9927-9

Sips R (1948) The Structure of a Catalyst Surface J Chem Phys 16:490-495 doi:org/10.1063/1.1746922 
Sotolongo-Grau. O, Rodríguez-Pérez. D, Antoranz. J. C, Sotolongo-Costa. Oscar (2010) Tissue Radiation Response with Maximum Tsallis Entropy Phys Rev Lett 105:158105

Sotolongo-Grau. O, Rodriguez-Perez. D, Sotolongo-Costa. O, Antoranz. J. C (2013) Tsallis entropy approach to radiotherapy treatments Phys A: Stat Mech Appl 392:2007-2015 doi:https://doi.org/10.1016/j.physa.2013.01.020

Stanislavsky A, Weron K (2013) Is there a motivation for a universal behaviour in molecular populations undergoing chemical reactions? Phys Chem Chem Phys 15:15595-15601 doi:10.1039/C3CP52272E

Temkin MI (1941) Adsorption equilibriumand kinetics of process on non homogeneous surfaces and in the interaction between adsorbed molecules J Phys Chem 15:296-233

Tonkin JA, Shamsudeen S, Martyn RB, Rita ES, Paul R, Huw DS (2014) Optical tracking of drug release from porous silicon delivery vectors The Institution of Engineering and Technology Optoelectronics 8:113-116 doi: $\underline{\text { http://dx.doi.org/10.1049/iet- }}$ opt.2013.0080

Tsallis C (2009) Nonadditive entropy and nonextensive statistical mechanics -an overview after 20 years Brazilian Journal of Physics 39:337-356 doi:http://dx.doi.org/10.1590/S0103-97332009000400002

Volesky B (2007) Biosorption and me Water Res 41:4017-4029 doi:https://doi.org/10.1016/j.watres.2007.05.062

Weber WJ, Morris JC (1963) Kinetics of adsorption on carbonfrom solution J Sanitary Eng Div 89:31-60

Wu F-C, Tseng R-L, Juang R-S (2009) Characteristics of Elovich equation used for the analysis of adsorption kinetics in dye-chitosan systems Chem Eng J 150:366-373 doi:https://doi.org/10.1016/j.cej.2009.01.014 


\section{Figure caption}

Figure 1: Effect of contact time and initial concentration on: (a) $\mathrm{MB}$ at $\mathrm{pH} 8$; and (b) $\mathrm{MO}$ at $\mathrm{pH} 2.5$ onto $\mathrm{F} 300$ at $25^{\circ} \mathrm{C}$ (lines are just guides for the eye).

Figure 2: Effect of $\mathrm{pH}$ and temperature on the adsorbed amount onto F300 of: (a) MB; and (b) $\mathrm{MO}$, both at $C_{0}=10 \mathrm{mg} / \mathrm{L}$.

Figure 3: Effect of $\mathrm{pH}$ and temperature on the free energy of adsorption $\Delta G^{\circ}$ onto the four ACs of: (a) MB; and (b) MO, both at $C_{0}=10 \mathrm{mg} / \mathrm{L}$.

Figure 4: Effect of $\mathrm{pH}$ on: (a and b) standard adsorption enthalpy $\Delta H^{\circ}$; and (c and d) on standard adsorption entropy $\Delta S^{\circ}$ for: (a and c) MB; and (b and) MO onto the four ACs.

Figure 5: BSf $(1, \alpha)$ kinetics model applied to the adsorption of: $(a, b) \mathrm{MB}$; and (c,d) MO onto F300 for different $\mathrm{pH}$ and temperatures, using an initial dye concentration $C_{0}=10 \mathrm{mg} / \mathrm{L}$.

Figure 6: Variation with $\mathrm{pH}$ and temperature of $\mathrm{BSf}(1, \alpha)$ parameters: (a) $\tau_{C}$; and (b) $\alpha$, for the adsorption onto F300 of $\mathrm{MB}$ and $\mathrm{MO}$ (both at $C_{0}=10 \mathrm{mg} / \mathrm{L}$ ).

Figure 7: Fits of the BG isotherm to the adsorption data onto F300 of: (a and b) MB; and (c and d) MO, for different temperatures and $\mathrm{pH}$.

Figure 8: Variation with $\mathrm{pH}$ and temperature of $\mathrm{BG}$ parameters, $a$ and $b$, determined by adsorption of: (a and c) MB; (b and d) MO, onto F200, F300, Acticarbone ${ }^{\circledR}$ and Cecalite ${ }^{\circledR}$. 


\section{List of table}

Table 1 : Characteristics of the four ACs used herein (Selmi et al. 2018c): surface area $\left(S_{B E T}\right)$, total pore volume measured by nitrogen adsorption at $-196^{\circ} \mathrm{C}\left(V_{t o t}\right)$, total amount of surface functional groups, and $\mathrm{pH}$ at the point of zero charge $\left(\mathrm{pH}_{P Z C}\right)$.

Table 2: Kinetic models derived from the BSf kinetic model

Table 3: Adsorption isotherms models derived from the GBS isotherm. 